\title{
In vitro Phytochemical, Larvicidal and Antimicrobial Activities of Gum Arabic Extract
}

\author{
Kauther Sir EIkhatim ALI ${ }^{1}$, Tanzeel Altaib Ali SALIH ${ }^{1}$ and \\ Hussien M. DAFFALLA ${ }^{2, *}$ \\ ${ }^{I}$ College of Applied and Industrial Sciences, Department of Biotechnology, University of Bahri, \\ Khartoum, Sudan \\ ${ }^{2}$ Commission for Biotechnology and Genetic Engineering, National Centre for Research, \\ Khartoum, Sudan
}

("Corresponding author's e-mail: hdaffalla@yahoo.com)

Received: 28 April 2018, Revised: 3 December 2018, Accepted: 18 January 2019

\begin{abstract}
The Gum Arabic of Acacia senegal (GA) has been reported to treat several diseases, such as kidney failure and cardiovascular and gastrointestinal disease. However, scarce investigation has been made into the phytoconstituents of GA. Obtained GA was macerated in water, then GA aqueous extract was subjected to phytochemical analysis using standard protocols and bioactivity screening by different procedures. Antimicrobial screening was performed using the cup-plate diffusion method against four bacterial strains and one fungi strain. The larvicidal activity was evaluated against the third instar of Culex quinquefasciatus. The phytochemical analysis showed that GA extract contains high amounts of saponins and alkaloids, moderate amounts of cardiac glycosides, and trace amounts of tannins. GA extract exhibited antimicrobial activity against the test organisms, with different zones of inhibition ranging 0 - 18 $\mathrm{mm}$. The larvicidal activity showed significant perfection with increasing extract dose and exposure period with mortality up to $86.7 \%$. Results reveal that the crude extract of GA contains important biomolecules which has been proved to have substantial larvicidal and antimicrobial activities.
\end{abstract}

Keywords: Acacia senegal, Antimicrobial, Culex quinquefasciatus, gum Arabic, secondary metabolites

\section{Introduction}

Gum Arabic (GA) is a natural, water-soluble, multiuse, and edible substance. It is an exudate from injured or intentionally tapped branches of Acacia senegal var. senegal (L.) Willdenow, or closely related species of Acacia (Leguminosae) such as A. polyacantha and A. seyal; it comes mainly from Sudan. When the duct of the inner bark of $A$. senegal is wounded during dry season, a sticky gummy substance appears and dries to form hard nodules in 3 - 8 weeks [1]. The hand-picked nodules represent a valuable source for rural people in Sudan to cover carbohydrate consumption and to treat many diseases.

In folk medicine, GA is employed to prepare various remedies to cure cough, diarrhea, sore throat, dysentery, gonorrhea, typhoid, urinary tract infections, and intestine inflammation [2-5]. Also, it is used externally to cover inflamed surfaces such as burns, wounds, sore nipples, and nodular leprosy $[3,5,6]$. Clinically, GA has been used in intravenous injections for the treatment of wound shock during the First World War, to induce antibodies, and to identify blood group antigens [7]. Recent research has asserted that GA possesses antioxidant, nephroprotectant, anti-cancer, anti-malarial, anticoagulant, immunemodulatory, cytoprotective, remineralization, biofungicidal, analgesic, astringent, emollient, liver tonic, antipyretic, anti-asthmatic, and metabolism of lipids properties [8-10]. The inclusive bioactivities indicate that GA contains different chemotherapeutic agents. Although several phytochemistry works have been 
http://wjst.wu.ac.th

reported on the pods, flowers, leaves, heartwood, bark, and roots of $A$. senegal, rare investigations have been made into the gum. Flavone, catechin, polyphenols, tannins, chalcones, alkaloids, and flavonoids have been identified in GA extracts [11].

A few studies have been reported on the antimicrobial activity of GA, including against several human pathogenic bacterial and fungi [5], inhibition activity against three food rotten microorganisms [8], against twelve different microorganisms [9], and cariogenic oral bacteria [10]. On the other hand, no insecticidal or larvicidal activities have been reported in GA extracts.

Currently, using phytochemicals for health, food, agricultural, and other needs has been preferred over synthetic substances. This tendency has resulted from some adverse effects raised from using chemical agents; mainly drug side effects, poisonousness to human, toxicity extended to beneficial organisms, drug resistance, environmental pollution, non-biodegradable nature, etc. To exploit the biologically active compound from plants, Sasidharan [12] determined the foremost stages to be conducted, namely extraction, pharmacological screening, isolation and characterization of bioactive compound, and toxicological and clinical evaluation. Therefore, the aim of this study was to screen the phytochemical content and the bioactivity of GA aqueous extract in terms of antimicrobial and mosquito larvicides.

\section{Materials and methods}

\section{Reagents/chemicals materials}

All the chemicals and reagents used in this study were of analytical grade. Dimethyl sulfoxide (DMSO), acetic anhydride, sulfuric acid, gelatin salt, and ferric chloride (purity 95 - $99.87 \%$ ) were obtained from Sigma-Aldrich (Germany). Other chemicals, such as aluminum chloride and potassium hydroxide, were from SDFCL (India). Purified distilled water was prepared in the laboratory. All glassware was from Marienfeld (Germany) and Exax (USA), and filter paper and discs were from Whatman. An oven, water bath, and incubator were from Nüve, Turkey.

\section{Collection of gum material and extraction}

The gum Arabic (GA) was collected in October 2016 form Acacia senegal var. senegal trees naturally growing in Abkrusholla, South Kordofan State, Sudan. The collected GA was crunched into ground powder and stored in containers until use. About $30 \mathrm{~g}$ of gum material was macerated in $100 \mathrm{~mL}$ distilled water until being dissolved with the assistance of a magnetic stirrer, then left at ambient temperatures $\left(25-30^{\circ} \mathrm{C}\right)$ for $24 \mathrm{~h}$ for more hydration. The extract was filtered with Whatman filter paper No. 41 and evaporated under room temperature. All extracts were stored at $4{ }^{\circ} \mathrm{C}$ until use in the experiments.

\section{Phytochemical analysis}

The phytochemical analysis of GA extract was assessed using standard protocols of analysis $[2,12,13]$. Qualitative detections were performed to determine the presence of different constituents individually, as described below. For each test, $1.0 \mathrm{~mL}$ of the gum extract was placed in a petri dish, dried in a water bath, and the obtained weight used for the phytochemical analyses.

The test for alkaloids was carried out by dissolving 3.0 gm of extract in $10 \mathrm{~mL} \mathrm{HCl} 2 \%$ or $\mathrm{NH}_{4} \mathrm{OH}$ $10 \%$ in three test-tube for each; then, Drogndroff's, Wagner's, and Mayer's reagents were added separately. For tannin analysis, $2.0 \mathrm{~g}$ of extract was dissolved in $10 \mathrm{~mL}$ ethanol, half of the solution used to test with ferric chloride, and half with gelatin salt. Triterpenes and sterols were tested as $1.0 \mathrm{~g}$ of extract dissolved in $6 \mathrm{~mL}$ of chloroform, and then a few drops of sulfuric acid added; the upper green layer indicated the presence of sterol, and the lower red brown ring indicated triterpenes. The Saponin test was performed by dissolving $0.5 \mathrm{~g}$ of extract in $10 \mathrm{~mL}$ of distilled water, vigorously shaking it for 30 seconds, allowing it to stand, and then observing it for the formation of foam. For cardiac glycosides, 0.1 $\mathrm{g}$ of extract was added to $1 \mathrm{~mL}$ glacial acetic acid anhydrite, containing one drop of ferric chloride plus 1 $\mathrm{mL}$ sulfuric acid. Coumarin content was analyzed in $1.0 \mathrm{~g}$ extract that was dissolved in $10 \mathrm{~mL}$ distilled water in a test tube, and a filter paper saturated with vapor resulting from adding drops of $0.5 \mathrm{~N} \mathrm{KOH}$ was 
http://wjst.wu.ac.th

inspected under UV light. The Anthraquinone test was performed by dissolving $0.1 \mathrm{~g}$ extract in $1.0 \mathrm{~mL}$ distilled water, adding $5.0 \mathrm{~mL}$ of chloroform, shaking for $5 \mathrm{~min}$, and adding $1.0 \mathrm{~mL}$ of ammonia solution $(10 \%)$ per $1.0 \mathrm{~mL}$ of chloroform fraction. The presence of flavonoids was determined by adding $1.0 \mathrm{~g}$ extract to $10 \mathrm{~mL}$ of ethanol, then transferring into four tests tube, and adding either $\mathrm{NaOH}$, magnesium plus one drop of $\mathrm{H}_{2} \mathrm{SO}_{4}$ in water bath, aluminium chloride $1 \%$ in methanol plus concentrated $\mathrm{HCl}$, or ammonium solution.

\section{Antimicrobial activity}

\section{Test organisms}

Microorganisms used in the present study included four bacteria: two Gram (+) Bacillus subtillis (NCTC 8236), Staphylococcus aureus (ATCC 25923), and two Gram (-) Escherichia coli (ATCC 25922), Pseudomonas arginosa (ATCC 27853), and one fungi Candida albicans (ATCC 7596).

The aseptically cultured microorganisms were washed off with normal saline to produce a suspension of $10^{10} \mathrm{CFU} / \mathrm{mL}$. The stock suspensions were diluted, and $0.02 \mathrm{~mL}$ were used as inoculum in the experiments. The average number of developed colonies in each drop $(0.02 \mathrm{~mL})$ was counted after incubation [14]). The suspension was maintained on desired media agar slants, stored at $4{ }^{\circ} \mathrm{C}$, and subcultured periodically.

\section{Bioassay}

The cup-plate agar diffusion method [15] was adopted with some minor modifications to assess the antimicrobial activity of the gum extract. One $\mathrm{mL}$ of the standardized bacterial stock suspension $10^{8}-10^{9}$ $\mathrm{CFU} / \mathrm{mL}$ was thoroughly mixed with $100 \mathrm{~mL}$ of molten sterile nutrient agar, which was maintained at 45 ${ }^{\circ} \mathrm{C}$. Aliquots of $20 \mathrm{~mL}$ nutrient (sabouraud dextrose for fungi) agar were used and were distributed into sterile Petri-dishes. The agars were left to set, and in each of these plates 4 cups (10 $\mathrm{mm}$ in diameter) were cut using a sterile cork borer (No. 4) and agar discs were removed. The cups were filled with $0.1 \mathrm{~mL}$ of the extract and allowed to diffuse at room temperature for two hours. Three extract concentrations of 2.5, 5 and $10 \mathrm{mg} / \mathrm{mL}$ were used for the determination of antimicrobial activity. Ciprofloxacin (antibacterial) and ketoconazole (antifungal) in a concentration of $5 \mathrm{mg} / \mathrm{mL}$ were used as a positive control, and DMSO was used as a negative control. The plates were then incubated at $37{ }^{\circ} \mathrm{C}$ for $18 \mathrm{~h}$ (for bacteria), or at $25^{\circ} \mathrm{C}$ for $48 \mathrm{~h}$ (for fungi). After incubation, the diameters of the resultant growth inhibition zones were measured.

\section{Larval bioassay}

The larvicidal activity of the prepared gum water extracts at different concentrations was determined using larvae of Culex quinquefasciatus assay, according to the WHO [16] method. The eggs of Culex were collected from rainy season swamps in Kadrow area, Khartoum North, Sudan. The collected eggs were transferred into open petri dishes contained distilled water with powdered bread. The eggs were incubated for 4 - 6 days at ambient conditions $\left(28 \pm 2{ }^{\circ} \mathrm{C}, 70 \pm 5 \% \mathrm{RH}\right.$, and $12 \mathrm{~h}$ light $)$ until arriving at the larval phase. The third instar larvae of Culex were identified according to the morphological characteristics of common C. quinquefasciatus larvae in Sudan [17]. Stock solution of larvicide was prepared by adding $50 \mathrm{mg}$ of the extract into $5 \mathrm{~mL}$ of DMSO. The larvicidal activity of extract was carried against larvae of Culex at the concentrations $0.0,5.0,50$, and $500 \mu \mathrm{L}$. The control concentration consisted of $2 \mathrm{~mL}$ DMSO. Thirty larvae were released in $200 \mathrm{~mL}$ water and treated with the desired concentration. Dead larvae were taken after $24 \mathrm{~h}$ and $48 \mathrm{~h}$ of incubation, and results on mortality percentage were calculated using formula (1). The larvae were considered dead when they were incapable of moving even after being inspired to with a needle or when water was disturbed. The $\mathrm{LC}_{50}$ (lethal concentration that kills $50 \%$ of the exposed larvae) and $\mathrm{LC}_{95}$ (lethal concentration that kills $95 \%$ of the exposed larvae) values were calculated based on mortality data using probit analysis [18].

Mortality $(\%)=\frac{\text { Number of death larvae }}{\text { Number of larvae introduced }} \times 100$ 
http://wjst.wu.ac.th

\section{Statistical analysis}

All experiments were conducted in triplicate. One-way analysis of variance (ANOVA) was carried out using genstate procedure [19]. The means separation was performed using Duncan's multiple range test at $5 \%$ significance. The results were presented as mean and standard error (mean $\pm \mathrm{SE})$.

\section{Results and discussion}

The extractive relative percentage yield GA using water was found to be $11.23 \% \mathrm{w} / \mathrm{w}$, with the physical appearance colorless and gummy. The extractive value indicated the presence of polar secondary metabolites. This was an approximate measure of the chemical constituents present in the gum. Also, it assisted in determination of the adulteration and impurities of the plant derived drug.

\section{Phytochemical screening of GA}

The result, in Table 1, showed higher amounts of alkaloids and saponin, moderate amounts of cardiac glycosides, and trace amounts of tannins. Flavonoids, sterol/triterpene, anthraquinone, and coumarin were not detected in the studied sample. This agreed partly with Marwah et al. [11], which reported that GA contains alkaloids and tannins. However, both studies reported that GA contained other secondary metabolites, such as flavone, catechin, chalcones, and flavonoids, which were not detected herein. Inversely, Evans et al. [2] stated that a $10 \%$ aqueous solution of GA gives no reaction for tannin with ferric chloride if of pharmacopoeial quality.

Other plant parts of $A$. senegal have been screened for secondary metabolites contents. The bark of A. senegal revealed the presence of tannins, saponins, and sterols, while alkaloids, glycosides, and flavonoids were not detected [20]. In contrast, alkaloids, glycosides, and flavonoids have been detected in A. senegal stem [21]. Abdel-Farid et al. [22] studied the metabolic profiling of the leave, flower, and pod parts of three Acacia species, viz. A. nilotica, A. seyal, and A. laeta. The results showed that plant parts, as well as species, affected the presence and the concentration of the phytochemicals studied.

Table 1 Phytochemical screening of secondary metabolites in gum Arabic extract

\begin{tabular}{|c|c|c|}
\hline Phytochemical & Tests used & Quantity index ${ }^{*}$ \\
\hline \multirow{3}{*}{ Alkaloids $\left(10 \% \mathrm{NH}_{4} \mathrm{OH}\right)$} & Drogndroff & - \\
\hline & Wagner & - \\
\hline & Mayer & - \\
\hline \multirow[t]{3}{*}{ Alkaloids ( $\mathrm{HCl}$ methanolic) } & Drogndroff & +++ \\
\hline & Wagner & +++ \\
\hline & Mayer & +++ \\
\hline \multirow[t]{4}{*}{ Flavonoids } & $\mathrm{NaOH}$ & - \\
\hline & $\mathrm{AlCl}_{3}$ & - \\
\hline & $\mathrm{Mg} / \mathrm{H}_{2} \mathrm{SO}_{4}$ & - \\
\hline & $\mathrm{NH}_{4} \mathrm{OH}$ & - \\
\hline \multirow[t]{2}{*}{ Tannins } & Ferric Chloride & + \\
\hline & Gelatin & + \\
\hline Saponins & & +++ \\
\hline Sterols and Triterpenes & & - \\
\hline Coumarin & & - \\
\hline Cardiac Glycosides & & ++ \\
\hline Anthraquinone & & - \\
\hline
\end{tabular}

*The quantity of the phytochemical is estimated by using the intensity of the test color as indicator; $(+++)$ high, $(++)$ moderate, $(+)$ trace amounts, $(-)$ not detected. 
http://wjst.wu.ac.th

In general, the bioactive compounds were created by plants for protection against bacteria, i.e., phytoprotectants, and are responsible for the antimicrobial activity of GA [5]. Alkaloids have been shown to be effective anti-feeding against herbivorous pests, including insects and mammals. Also, alkaloids have toxic effects against some fungi and bacteria strains. The evidence for this role is increasing. Saponins are very useful in the treatment of upper respiratory tract inflammation and are reported to have anti-diabetic and anti-fungal properties. Cardiac glycosides are highly toxic plant secondary compounds. They are inhibitors of the plasma membrane $\mathrm{Na}+\mathrm{K}$-ATPase that are used for the treatment of heart failure. Also, cardiac glycosides are responsible for the poisoning of livestock. Tannins possess physiological astringents and are therefore used for treating intestinal disorders such as diarrhea and dysentery, and wound healing and ameliorate-inflamed mucus membrane. The typical effect of tannins is the inhibition of cell protein synthesis resultant from irreversible complex reaction with the proline-rich protein [23].

\section{Antimicrobial activity}

The crude extracts of Arabic gum at concentrations of $2.5,5$, and $10 \mathrm{mg} / \mathrm{mL}$ were subjected to antimicrobial assays by using the Cup plate method, and the inhibition zones were measured (mm) against four bacterial organisms (two gram positive; B. subtilis, S. aureus and two gram negative; E. coli, $P$. arginosa) and one fungal organisms (C. albicans); mean activities are shown in Figure 1.

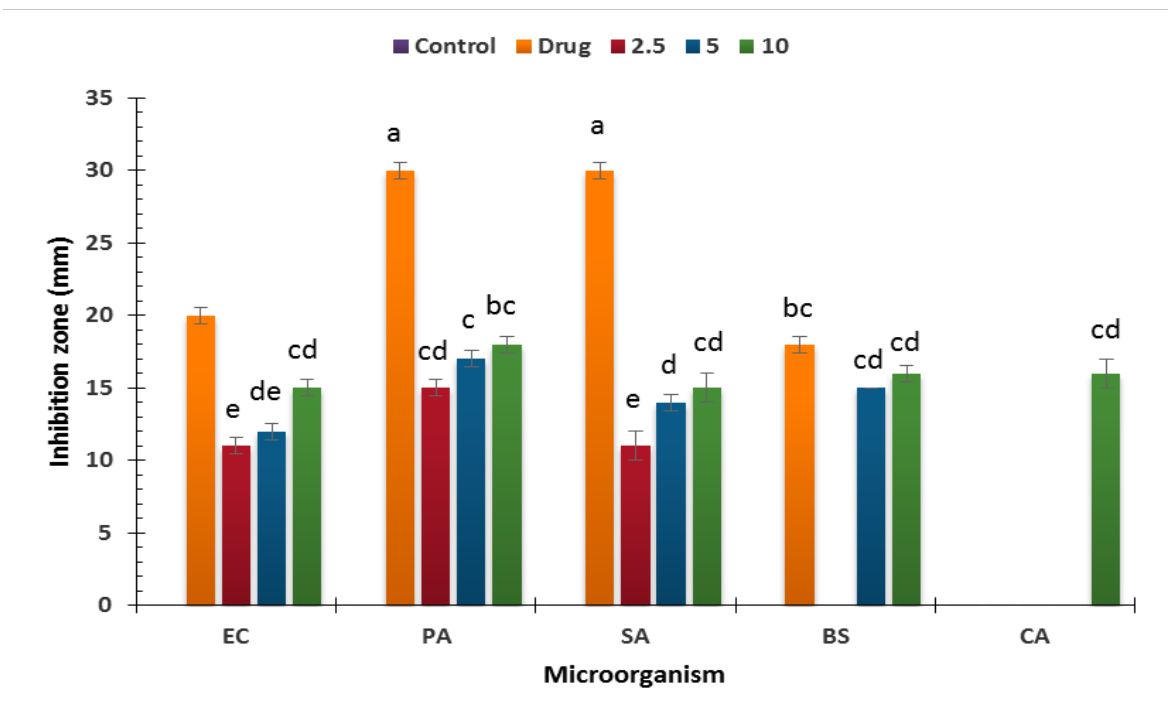

Figure 1 Antimicrobial activity of GA extract in different concentrations $0.0,2.5,5$, and $10 \mathrm{mg} / \mathrm{mL}$ and standard antibiotics (ciprofloxacin and ketoconazole). The activity was expressed in terms of diameter of zone of growth inhibition in mm. Vertical bars represent standard errors. EC: Escherichia coli, PA: Pseudomonas arginosa, SA: Staphylococcus aureus, BS: Bacillus subtilis, CA: Candida albicans, GA: gum Arabic.

The aqueous extract of GA showed variable inhibitory effects, depending on the concentration and the microorganism type. Only the concentration $10 \mathrm{mg} / \mathrm{mL}$ showed effectiveness against all the microorganisms. The concentrations 2.5 and $5 \mathrm{mg} / \mathrm{mL}$ had no significant effect against the fungi $C$. albicans (Figure 1). Also, $2.5 \mathrm{mg} / \mathrm{mL}$ had no significant effect against $B$. subtilis (Figure 1). For clarity of the results, the size of diameter of the inhibition zone was expressed as $<9 \mathrm{~mm}$ : inactive, $9-12 \mathrm{~mm}$ : partially active, $13-18 \mathrm{~mm}$ : active, and $>18 \mathrm{~mm}$ : very active. Accordingly, the extract at concentration 
http://wjst.wu.ac.th

$10 \mathrm{mg} / \mathrm{mL}$ was active against $E$. coli, $S$. aureus, B. subtilis, and $C$. albicans, and very active against $P$. aeruginosa.

Similarly, GA showed a moderated effect against $P$. aeruginosa, while Micrococcus luteus and $B$. subtilis were unaffected by the presence of GA [8]. Alawi et al. [5] studied antimicrobial activity using different organic fractions of GA from two sources against S. aureus, E. coli, and Klebsiella pneumonia. The Sudanese GA showed higher antimicrobial activity against all bacterial strains. Similar to the present study, water extracts showed moderate activity against all bacterial strains. In another study, GA exhibited a moderate inhibition activity against Streptococcus mutans [10]. Furthermore, Bnuyan et al. [9] compared the antimicrobial activities of aqueous extracts of commercial gum samples of $A$. senegal and $A$. syeal against elven bacterial strains and one fungus. The results revealed that GA ( $A$. senegal) was highly active against only S epidermidis, St. pneumoniae, K. pneumoniae, Serratia spp., and C. albicans, while $A$. syeal displayed superior activity against all the tested microorganisms. On the other hand, gum from other Acacia showed growth inhibitory activities, such as A. arabica, on Prophyromonas gingivalis and Prevotella intermedia [24].

The antimicrobial effects of GA may be due to the presence of high amounts of alkaloids and saponins that were detected in the extract. Extracts of different parts of A. senegal also exhibited antimicrobial activities. Various organic solvent extracts of $A$. senegal root-heartwood revealed significant activity against E. coli, S. aureus, and C. albicans [3]. Hexane extract of the bark showed activity against $S$. aureus and the fungus $C$. albicans, while methanol extract showed activity against $E$. coli, B. cereus, and fungi C. albicans and A. niger [6].

\section{Larvicidal activity}

Investigation of the larvicidal activity of GA (Acacia senegal gum) was carried out for the first time. The preliminary experiment (Table 2) concluded that $C$. quinquefasciatus was sensitive to GA extract. However, the same value of $86.7 \%$ mortality occurred by the maximum concentration $(500 \mu \mathrm{L})$ within $24 \mathrm{~h}$ and $48 \mathrm{~h}$. The effect was dose dependent and significantly different $(P<0.05)$ between concentrations and from the control in all cases. Increasing the exposure period resulted in a progressive increase in mortality by the lower concentrations $(5,50 \mu \mathrm{L})$. Likewise, the smallest values of $\mathrm{LC}_{50}$ and $\mathrm{LC}_{95}$ were obtained in $48 \mathrm{~h}$ (Table 3), indicating that increasing the exposure time enhanced the larvicidal activities compared to $24 \mathrm{~h}$. A similar effect of exposure times was reported by Kamaraj et al. [25], where $A$. concinna seed extracts nearly doubled the mortality in C. quinquefasciatus larvae after $48 \mathrm{~h}$.

Table 2 Larvicidal effect of GA extract on Culx quinquefasciatus $3^{\text {rd }}$ instar larvae after 24 and $48 \mathrm{~h}$

\begin{tabular}{llll}
\hline \multirow{2}{*}{ Extract $(\boldsymbol{\mu L})$} & \multirow{2}{*}{ Number of larvae } & \multicolumn{2}{l}{ Parentage mortality (mean $\pm \mathbf{S E})$} \\
\cline { 3 - 4 } & & $\mathbf{2 4} \mathbf{~ h}$ & $\mathbf{4 8 ~ h}$ \\
\hline 0 & 30 & $0.0 \pm 0.0^{\mathrm{d}}$ & $0.0 \pm 0.0^{\mathrm{d}}$ \\
5 & 30 & $13.33 \pm 0.2^{\mathrm{c}}$ & $14.44 \pm 2.9^{\mathrm{c}}$ \\
50 & 30 & $66.67 \pm 1.9^{\mathrm{b}}$ & $73.33 \pm 5.1^{\mathrm{ab}}$ \\
500 & 30 & $86.67 \pm 1.0^{\mathrm{a}}$ & $86.67 \pm 1.9^{\mathrm{a}}$ \\
\hline
\end{tabular}

Different letters within the column indicate statistically significant differences between means according to Duncan's multiple range test $(P<0.05)$. GA: gum Arabic, SE: standard errors. 
http://wjst.wu.ac.th

Table 3 Lethal dose of GA aqueous extract against Culex quinquefasciatus $3^{\text {rd }}$ instar larvae after 24 and $48 \mathrm{~h}$

\begin{tabular}{lllll}
\hline Exposure period & $\mathbf{L C}_{\mathbf{5 0}} \boldsymbol{\mu L}\left(\mathbf{L C}_{\mathbf{5 0}} \mathbf{L o g}\right)$ & $\mathbf{L C}_{\mathbf{9 5}} \boldsymbol{\mu L}\left(\mathbf{L C}_{\mathbf{9 5}} \mathbf{L o g}\right)$ & Regression equation & $\mathbf{r}^{\mathbf{2}}$ \\
\hline $24 \mathrm{~h}$ & $32.74(1.515)$ & $653.75(2.8154)$ & $y=34.605 x-2.4274$ & 0.9612 \\
$48 \mathrm{~h}$ & $28.58(1.4561)$ & $545.77(2.737)$ & $y=35.131 x-1.1538$ & 0.9363 \\
\hline
\end{tabular}

$\mathrm{LC}_{50}$ : lethal concentration that kills $50 \%$ of the exposed larvae, $\mathrm{LC}_{95}$ : lethal concentration that kills $95 \%$ of the exposed larvae, $\mathrm{r}^{2}$ : regression coefficient.

This larvicidal effect reported in the present study may be attributed to high viscosity characterized GA, which inhibits the movement and uptake of nutrients by larvae. Additionally, the existence of high amounts of acidic alkaloid saponin, cardiac glycosides, and tannins has a toxic effect on the larvae.

To the best of knowledge, no larvicidal activities of gums from any Acacia species have been reported. However, extracts of different parts of various Acacias exhibited varied activities against $C$. quinquefasciatus. Compared with those previous studies, GA extracts in the present study showed medium values of $32.74 \mu \mathrm{L}\left(\mathrm{LC}_{50}\right)$ and $653.75 \mu \mathrm{L}\left(\mathrm{LC}_{95}\right)$, as essential oil from seed of $A$. nilotica showed $5.23 \mathrm{mg} / \mathrm{L}\left(\mathrm{LC}_{50}\right)$ and $9.71 \mathrm{mg} / \mathrm{L}\left(\mathrm{LC}_{90}\right)$ [26], and acetone extract from leaf of $A$. ferruginea showed $5362.6 \mathrm{ppm}\left(\mathrm{LC}_{50}\right)$ and $5630.2 \mathrm{ppm}\left(\mathrm{LC}_{90}\right)$ [27]. Insecticidal effects of plant extracts varied not only according to mosquito species, geographical varieties, or plant species and parts used, but also due to extraction methodology and the polarity of the solvents used [28].

Generally, the dissimilarities in the bioactivities of GA can be accredited to variations in the sources of $A$. senegal gums. The principal gum origin variables, including age of the trees, climatic conditions, and soil environment, greatly affected the gum constitutes and structure [29]. A simple immunological analysis of 16 gum exudates obtained from 13 Acacia species displayed that each of the gum samples studied had a unique composition. Even more, gum obtained from different sub-species of a single species (e.g., A. nilotica has four sup-species) presented very distinct chemical compositions [7].

\section{Conclusions}

Gum Arabic ( $A$. senegal) extract was obtained using water as a solvent and had good effect on bacteria, fungi, and larvae. More research is needed on GA to determine the active component that generates antimicrobial and larvicidal activities. Further work on purification of gum extracts to isolate the bioactive metabolites and their structures must be elucidated.

\section{References}

[1] PA Williams, OHM Idris and GO Phillips. Structural Analysis of Gum from Acacia senegal (Gum Arabic). In: Nothnagel et al. (Eds.). Cell and Developmental Biology of Arabinogalactan-Proteins. Kluwer Academic/Plenum Publishers, 2000, p. 241-51.

[2] WC Evans, D Evans and GE Trease. Trease and Evans pharmacognosy. $16^{\text {th }} \mathrm{ed}$. Saunders/Elsevier, Edinburgh, 2009, p. 616.

[3] R Jain, P Sharma, T Bhagchandani and SC Jain. Phytochemical investigation and antimicrobial activity of Acacia senegal root heartwood. J. Pharm. Res. 2012, 5, 4934-8.

[4] AR Ndhlala, SO Amoo, B Ncube, M Moyo, JJ Nair and JV Staden. Antibacterial, Antifungal, and Antiviral Activities of African Medicinal Plants. Medicinal Plant Research in Africa, Elsevier, 2013, p. 621-59.

[5] SMA Alawi, MA Hossain and AA Abusham. Antimicrobial and cytotoxic comparative study of different extracts of Omani and Sudanese Gum acacia. Beni-Suef Univ. J. Basic Appl. Sci. 2018; 7, 22-6. 
http://wjst.wu.ac.th

[6] ML Saini, R Saini, S Roy and A Kumar. Comparative pharmacognostical and antimicrobial studies of Acacia species (Mimosaceae). J. Med. Plants Res. 2008, 2, 378-86.

[7] TC Baldwin, PE Quaha and AR Menzies. A serotaxonomic study of Acacia gum exudates. Phytochemistry 1999, 50, 599-606.

[8] MA Montenegro, ML Boiero, L Valle and CD Borsarelli. Gum Arabic: More Than an Edible Emulsifier, Products and Applications of Biopolymers. In: J Verbeek (Ed.). InTech, 2012, p. 220.

[9] IA Bnuyan, NL Hindi, MH Jebur and MA Mahdi. In vitro antimicrobial activity of gum Arabic prebiotics against infectious pathogens. Int. J. Pharm. Pharm. Sci. 2015, 3, 77-85.

[10] MMM Banjar, AM Khafaji and YA Maher. Antimicrobial activity of hydrogen peroxide, sesame and gum Arabic against Streptococcus. Int. J. Health Sci. Res. 2017, 7, 97 -104.

[11] RG Marwah, MO Fatope, RA Mahrooqi, GB Varma, HA Abadi and SKS Al-Burtamani. Antioxidant capacity of some edible and wound healing plants in Oman. Food Chem. 2007; 101, 465-70.

[12] S Sasidharan, Y Chen, D Saravanan, KM Sundram and LY Latha. Extraction, isolation and characterization of bioactive compounds from plants' extracts. Afr. J. Tradit. Compl. Altern. Med. $2011 ; 8,1-10$.

[13] AJ Harbone. Phytochemical Method: A Guide to Modern Techniques of Plant Analysis. $3^{\text {rd }}$ ed. Springer, Netherlands, 1998, p. 302.

[14] AA Miles and SS Misra. The estimation of the bactericidal power of the blood. J. Hyg. 1938; 38, 732-49.

[15] F Kavanagh. Analytical Microbiology. In: F Kavanagh (Ed.). Academic Press, New York \& London, 1972, p. 11.

[16] WHO. Guidelines for Laboratory and Field Testing of Mosquito Larvicides. Communicable Disease Control, Prevention and Eradication; WHO, Pesticide Evaluation Scheme, WHO, Geneva, Switzerland, 2005, p. 1-219.

[18] DJ Finney. Probit Analysis. $3^{\text {rd }}$ (Ed.). Cambridge University Press, London, 1971, p. 20-42.

[19] VSN International Ltd. GenStat Release 10.3. GenStat Discovery Edition 4, Gen Stat Procedure Library Release PL18.2, VSN International Ltd. (Rothamsted Experimental Station), 2011.

[20] SO Okoro, AH Kawo and AH Arzai. Phytochemical screening, antibacterial and toxicological activities of Acacia senegal extracts. Bayero J. Pure Appl. Sci. 2012; 5, 163-170.

[21] IY Suleiman, SA Yaro, M Abdulwahab, SA Salihu and OC Ogheneme. Phytochemical and spectroanalytical characterizations of some plants extract as green corrosion inhibitors. J. Mater. Environ. Sci. 2017; 8, 3423-32.

[22] IB Abdel-Farid, MG Sheded and EA Mohamed. Metabolomic profiling and antioxidant activity of some Acacia species. Saudi J. Biol. Sci. 2014; 21, 400-8.

[23] T Shimada. Salivary proteins as a defense against dietary tannins. J. Chem. Ecol. 2006; 32, 1149-63.

[24] DT Clark, MI Gazi, SW Cox, BM Eley and GF Tinsley. The effects of Acacia arabiea gum on the in vitro growth and protease activities of periodontopathic bacteria. J. Clin. Periodontol. 1993; 20, 238-43.

[25] C Kamaraj, A Abdul Rahuman, A Bagavan, G Elango, AA Zahir and T Santhoshkumar. Larvicidal and repellent activity of medicinal plant extracts from Eastern Ghats of South India against malaria and filariasis vectors. Asian Pac. J. Trop. Med. 2011; 4, 698-705.

[26] P Vivekanandhan, R Venkatesan, G Ramkumar, S Karthi, S Senthil-Nathan and MS Shivakumar. Comparative analysis of major mosquito vectors response to seed-derived essential oil and seed pod-derived extract from Acacia nilotica. Inte. J. Environ. Res. Public Health. 2018; 15, 388.

[27] R Vahitha, MR Venkatachalam, K Murugan and A Jebanesan. Larvicidal efficacy of Pavonia zeylanica L. and Acacia ferruginea D.C. against Culex quinquefasciatus Say. Bioresour. Technol. 2002; 82, 203-4.

[28] A Ghosh, N Chowdhury and G Chandra. Plant extracts as potential mosquito larvicides. Indian J. Med. Res. 2012; 135, 581-98.

[29] KS Ali and HM Daffalla. Physicochemical and functional properties of the gum arabic from Acacia senegal. Ann. Food Sci. Technol. 2018, 19, 27-34. 